\title{
Proteolytic Activity During the Growth of C6 Astrocytoma in the Murine Spheroid Implantation Model
}

\author{
Indrasen S. Vaithilingam, Warren McDonald, Eric C. Stroude, \\ Robert A. Cook and Rolando F. Del Maestro
}

\begin{abstract}
General protease and collagenase IV activity are involved in the remodelling of the vascular basement membrane that occurs during tumor-induced angiogenesis. This study has assessed the level of these enzymes in tumor, peritumoral or contralateral cerebral cortex tissue during the growth of C6 astrocytoma in the rat spheroid implantation model. General proteolytic activity was increased in tumor tissue beginning on day 8 following spheroid implantation, then increased to a maximum value on day 11 and decreased to control values on day 18 . A similar pattern was seen for collagenase IV activity but maximal activity occurred on day 13. The peritumor and tumor patterns of activity were similar. General protease activity was increased in the hemisphere contralateral to the tumor suggesting that the growth of $\mathrm{C} 6$ astrocytoma in rat brain was influencing biochemical events distant from the tumor. C6 astrocytoma cells orchestrate a cascade of proteolytic events which may play a crucial role in angiogenesis associated with tumor growth in the model system studied.
\end{abstract}

\begin{abstract}
RÉSUMÉ: Activité protéolytique pendant la croissance de l'astrocytome C6 chez le modèle murin d'implantation sphéroïde. L'activité protéolytique générale et la collagénase IV sont impliquées dans le remodelage de la membrane basale vasculaire qui survient lors de l'angiogenèse induite pars les tumeurs. Cette étude a évalué le niveau de ces enzymes dans les tumeurs, les tissus péritumoraux ou du cortex cérébral contralatéral, pendant la croissance de l'astrocytome C6, dans le modèle murin d'implantation sphéroïde. L'activité protéolytique générale était augmentée dans les tissus tumoraux à partir du huitième jour suivant l'implantation sphéroïde, puis augmentait jusqu'à une valeur maximale le onzième jour et revenait à des valeurs contrôles le dix-huitième jour. Un tableau similaire a été observé pour l'activité de la collagénase IV, l'activité maximale survenant cependent au treizième jour. L'expression de l'activité péritumorale et tumorale étaient similaires. L'activité protéolytique générale était augmentée dans l'hémisphère contralatéral à la tumeur, suggérant que la croissance de l'astrocytome C6 dans le cerveau du rat exercait une influence sur des événements biochimiques survenant à distance de la tumeur. Les cellules de l'astrocytome C6 orchestrent une cascade d'événements protéolytiques qui pourraient jouer un rôle crucial dans l'angiogenèse associée à la croissance tumorale dans le modèle étudié.
\end{abstract}

Can. J. Neurol. Sci. 1992; 19:17-22

Proteolytic activity is enhanced in a variety of tumor cell lines. $^{1-4}$ The highly metastatic mouse melanoma cell line, B16F10, contains elevated levels of plasminogen activator ${ }^{1}$ and cathepsin $\mathrm{B}^{2}$ when compared to $\mathrm{B} 16-\mathrm{F} 1$ which rarely forms secondary colonies. Collagenase type IV activity is increased in B16-F10 when compared to a number of less metastatic cell lines and hybrid lines maintained or had augmented collagenase type IV activity. ${ }^{3}$ Transfection of N1H-3T3 cells with ras oncogene increased both their expression of collagenase type IV activity and their metastatic potential in nude mice. ${ }^{4}$ Our initial in vitro studies utilizing a malignant rat astrocytic cell line, C6 astrocytoma, have indicated that general protease and collagenase IV activity are released extracellularly during early expo- nential growth of $\mathrm{C} 6$ cells in monolayer culture and C6 astrocytoma spheroids in spinner culture. ${ }^{5}$ These studies also indicate that the size of the implanted spheroid affects the level of proteolytic activity observed after 15 days of spheroid growth in the rat spheroid implantation model..$^{5}$ General protease and collagenase IV activity were frequently higher in tumor tissue than in control cerebral tissue. ${ }^{5} \mathrm{~A}$ cell line derived from a human malignant glial tumor, U-251, releases general protease and collagenase IV activity extracellularly but these activities are not augmented by the cytokine, tumor necrosis factor- $\alpha .^{6}$

The role played by extracellularly-released proteolytic activity in tumor growth and tumor-induced angiogenesis remains undefined. In a number of model systems, sustained tumor

From the Brain Research Laboratories, Experimental Research Unit, Department of Clinical Neurological Sciences, Victoria Hospital (ISV, WMcD, ECS, RFD), and the Department of Biochemistry (RAC), University of Western Ontario, London

Received May 15, 1991. Accepted in final form October 10, 1991

Reprint requests to: Dr. R.F. Del Maestro, Brain Research Laboratories, Victoria Hospital, 375 South Street, London, Ontario, Canada N6A 4G5 
growth is dependent on angiogenesis. ${ }^{7-11}$ Tumor microvessels originate from previously normal tissue microvessels and this involves a three stage process: initiation, propagation of endothelial cells and termination. ${ }^{10-13}$ Mignatti et al. have proposed that during angiogenesis associated with tumor growth, a cascade of proteolytic events occurs which leads to the degradation of the extracellular matrix. ${ }^{14,15}$ The basement membrane constitutes a specific component of the extracellular matrix. Non-fibrous proteins such as laminin, adhesive molecules and proteoglycans are integrated into the basement membrane. Collagen IV comprises up to $90 \%$ of the total protein of the basement membrane ${ }^{16}$ which forms the fibrous matrix that offers structural rigidity to the vessel wall. To adequately assess the breakdown of the basement membrane, the levels of general proteases or non-specific proteolytic activity which degrade the variety of non-fibrous protein components of the basement membrane, and collagenase IV activity which degrades collagen IV, should be assessed.

To define the relationship between tumor growth and proteolytic activity, the levels of general protease and collagenase IV activity have been assessed in tumor, peritumoral and contralateral cerebral cortex tissue during the growth of C6 astrocytoma cells in the rat spheroid implantation model. ${ }^{17}$ This model has many of the pathological and growth characteristics of human malignant gliomas including pseudopalisading, necrosis and hemorrhage and has been used extensively to study malignant glial cell in vivo (see review 13,17). The experiment was limited to 18 days of growth so that secondary events such as extensive tumor necrosis and/or hemorrhage which occur late in this model would not influence the levels of proteolytic activity measured.

\section{Materials AND Methods}

\section{Implantation of C6 Astrocytoma Spheroid}

Spheroids were grown from C6 astrocytoma cells in in vitro spinner culture. ${ }^{17}$ Single spheroids of $450 \mu \mathrm{m}$ size were implanted into the cerebral cortex of Sprague-Dawley rats. ${ }^{17}$ Cerebral cortex from unoperated animals was utilized as a control. A second control was necessary to correct for the introduction of a cortical lesion to implant the spheroid; thus perilesion tissue from lesion-only controls without the presence of a spheroid was also assessed. Cerebral tumor growth was monitored by excising the tumor and obtaining a wet weight and proteolytic activity in tumor and contralateral cerebral cortex tissue at 1,3 , $6,8,11,13,15$ and 18 days after implantation. Peritumoral tissue was available for days 8 through 18 . Tumor tissue, peritumoral tissue and contralateral cerebral cortex were analyzed for non-specific proteolytic activity and collagenase IV activity after homogenization of the respective samples in $50 \mathrm{mM}$ Tricine, $0.2 \mathrm{M} \mathrm{NaCl}, \mathrm{CaCl}_{2}$ at $\mathrm{pH} 7.5$.

\section{General Protease and Collagenase Assays}

Proteolytic activity was assayed by measuring the degradation of ${ }^{3} \mathrm{H} \alpha$-casein and ${ }^{3} \mathrm{H}$-collagen IV to products soluble in trichloroacetic acid. The $\alpha$-casein (Sigma) was radiolabelled with ${ }^{3} \mathrm{H}$-formaldehyde (NEN) following the procedure of Rice and Means. ${ }^{18}$ Collagen IV (Sigma) was radiolabelled with the same reagent by adapting the procedures of Mallya et al. ${ }^{19}$ and Mookhtiar et al. ${ }^{20}$ to collagen IV. The general protease assay was conducted in $50 \mathrm{mM}$ Tris- $\mathrm{Cl}, 50 \mathrm{mM} \mathrm{NaCl}$, and $10 \mathrm{mM}$ $\mathrm{CaCl}_{2}$ at $\mathrm{pH} 7.5$. The assays contained between 1 to $3 \mu \mathrm{g}$ of protein to maintain activity within the linear range. When $\alpha$-casein was used as the substrate the incubation mixture contained 10 $\mu \mathrm{g}$ of ${ }^{3} \mathrm{H} \alpha$-casein $(20,000 \mathrm{dpm})$ [provided by Dr. R.A. Cook] in a final volume of $0.5 \mathrm{ml}$. Assays utilizing collagen IV as the substrate contained $10 \mu \mathrm{g}$ of ${ }^{3} \mathrm{H}$ collagen IV $(10,000 \mathrm{dpm})$ and enzyme preparation in a final volume of $0.5 \mathrm{ml}$.

The incubations were conducted for $2 \mathrm{~h}$ at $37^{\circ} \mathrm{C}$ when $\alpha$ casein or ${ }^{3} \mathrm{H}$ collagen was utilized. Following incubation, $60 \mu \mathrm{l}$ of cold $100 \%$ trichloroacetic acid was added to precipitate the undigested proteins. The assay tubes were kept on ice for 30 min., the contents transferred to $1.5 \mathrm{ml}$ tubes and centrifuged at $12,000 \times \mathrm{g}$ for $5 \mathrm{~min}$. (Eppendorf). A $0.4 \mathrm{ml}$ sample of acid-soluble products was counted in a liquid scintillation counter (Beckman LS 3801). One unit of activity represents the amount of enzyme required to solubilize $1 \mu \mathrm{g}$ of $\alpha$-casein or $1 \mu \mathrm{g}$ of collagen IV per h at $37^{\circ} \mathrm{C}$. Specific activity is expressed as units per $\mathrm{mg}$ of protein.

\section{Protein Assay}

The method of Bradford ${ }^{21}$ using the Bio-Rad protein assay kit was employed. The standard curve was established using bovine serum albumin.

\section{Statistics}

The results reported in this study represent means \pm standard error of the mean. Statistical significance was determined through the use of the student unpaired t-test multiple comparisons where $\mathrm{p}<.01$ was considered significant.

\section{Results}

\section{Tumor Growth}

Tumor growth in the C6 astrocytoma spheroid implantation model is characterized by an initial lag phase to day 8 in which very little tumor growth is seen. This is followed by a slow growth phase (day 8-15) and then a rapid growth phase (day 1518) (Figure 3). This type of growth appears to characterize $C 6$ astrocytoma growth in this model. ${ }^{17}$

\section{General Proteolytic Activity}

Perilesion tissue from lesion-only controls contained some general proteolytic activity, but this was not significantly different from the value found for cortical tissue obtained from unoperated controls at any of the time periods studies (Figure 1). General proteolytic activity was significantly higher in tumor tissue compared to cerebral cortex removed from unoperated controls at day $8,11,13$, and 15 after spheroid implantation. The pattern in tumor tissue was increasing activity starting at day 8 , peaking on day 11 and then decreasing to values not significantly different from controls at day 18 . In peritumoral tissue, a very similar pattern was observed. General proteolytic activity increased faster in peritumoral than in tumor tissue, but peaked at a lower level and was still significantly higher at day 18. Peritumoral tissue expressed greater proteolytic activity than its tumor counterpart on day 18. Contralateral cortex was found to contain significantly higher levels of general protease activity than unoperated controls on day 11 although this was lower than that observed in peritumoral and tumor tissue. 


\section{Collagenase IV Activity}

The levels of collagenase IV activity in perilesion tissue obtained from lesion-only controls during the course of the experiment were not significantly different from that found in unoperated control cerebral cortex (Figure 2). In tumor tissue, collagenase IV activity began to increase on day 8 reaching a maximum on day 13 which was significantly different from unoperated control cerebral cortex followed by a rapid decrease to basal values on day 15 and 18 . A similar pattern was obtained for peritumoral tissue although the peak activity was only half that of tumor tissue. No significant differences in the level of collagenase IV activity was found in the contralateral cerebral cortex when compared to unoperated controls.

\section{General Protease Activity and Collagenase IV Activity and Tumor Growth}

The levels of general protease and collagenase IV activity in tumor tissue are related to tumor growth in Figure 3. The former activity peaked on day 11 and then fell to levels not significantly different from controls on day 18. Collagenase IV activity peaked on day 13 and then decreased to control levels by day 18 . Both types of enzymatic activity increased before the rapid phase of tumor growth occurred. During rapid tumor growth, proteolytic activity decreased. General protease activity appeared to peak two days before maximal collagenase IV activity. A similar pattern of activities was also detected in peritumoral tissue.

\section{Discussion}

The implantation of C6 astrocytoma spheroids into the cerebral hemisphere of Sprague-Dawley rats is associated with significant alterations in proteolytic activity in tumor tissue, peritumoral tissue and contralateral cerebral cortex. The introduction of a cerebral defect in the absence of a spheroid did not result in significant alterations of general protease or collagenase IV activities in perilesion tissue when compared to cerebral cortex from unoperated controls. This indicates that the increased proteolytic activity measured is related to the implantation and growth of the C6 astrocytoma cells contained in the spheroid.

The timing of the general protease and collagenase IV peaks may be important for tumor-induced angiogenesis. The controlled release and/or activation of general protease and collagenase IV activities is essential to the degradation of the vascular basement membrane and the remodelling of the normal angioarchitecture which occurs during the growth of C6 astrocytoma cells in this model. Conceptually, the initial extracellular release

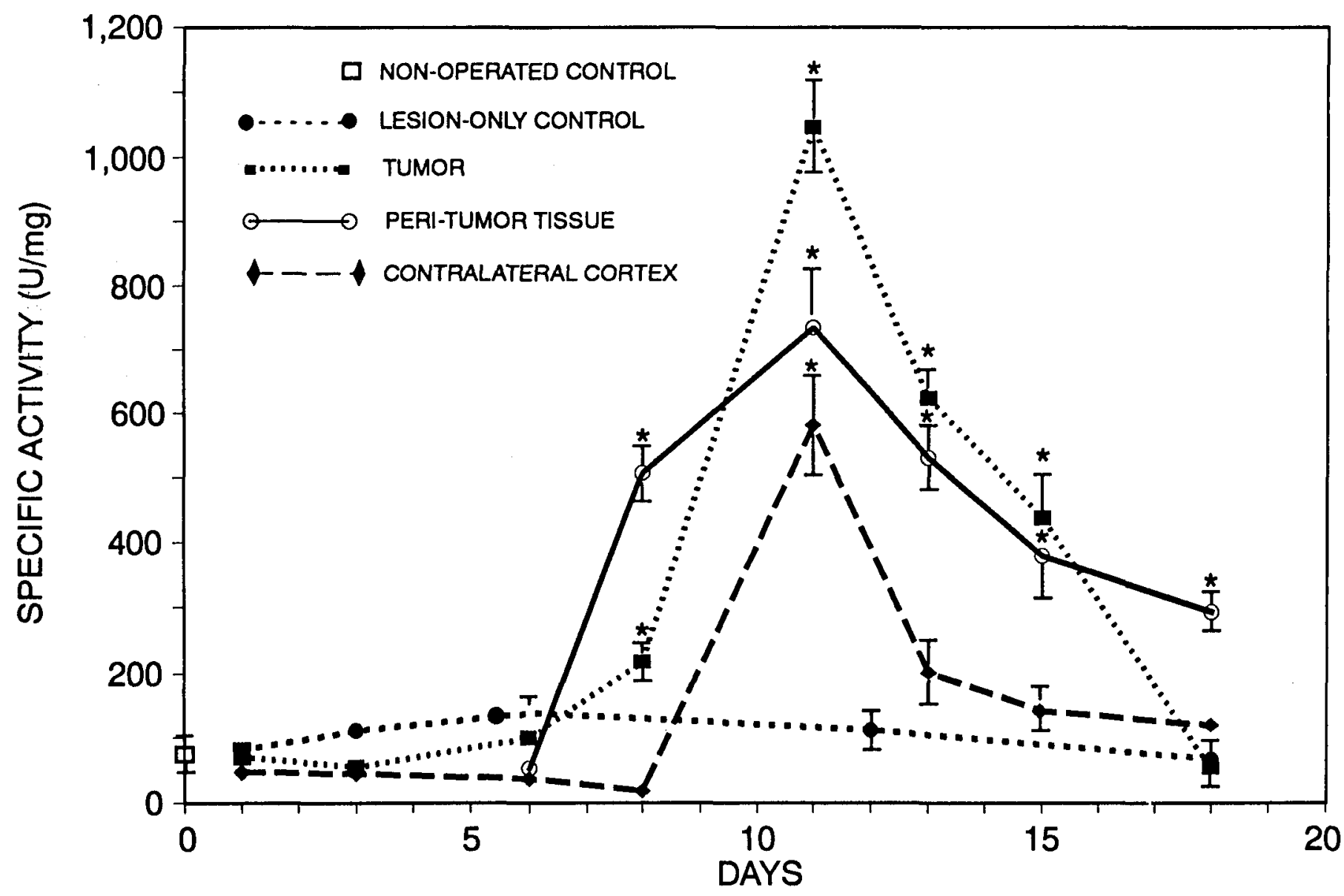

Figure 1 -General protease activity in non-operative cerebral tissue, lesion-only controls, tumor, peritumoral tissue and contralateral cortex during the growth of C6 astrocytoma cells in the spheroid implantation model. Values are means \pm standard error of the mean $(n=5)$. Significant differences $(p<0.01)$ from non-operative controls are indicated with an asterisk (*). 
and/or activation of a variety of general proteases may be necessary to expose the collagen IV of basement membrane to collagenase IV mediated degradation to allow the initiation of angiogenesis. The results of this study demonstrating that general protease activity peaks before collagenase IV activity would appear to be consistent with this concept. However, despite continued tumor growth, the levels of general protease and collagenase IV activity fall. The reasons for this fall in proteolytic activity are unknown, but could be related to an alteration in tumor growth patterns which may result in altered gene expression. In the rat C6 astrocytoma spheroid implantation model, tumor microvessels begin to appear 3-5 days post-implantation and these develop a loose branching network of large diameter microvessels between day 7 and $13 .{ }^{17}$ With continued tumor growth, some microvessels in peritumoral tissue are surrounded by tumor cells. ${ }^{13,17}$ Tumor cells grow along previously established normal blood vessels and alter their function in the latter stages of tumor development. This phenomenon, called tumorinduced vascular modification, ${ }^{13}$ may also be an important mechanism by which tumors can acquire a vasculature. ${ }^{22}$ The invasion of tumor cells along blood vessels may involve other proteolytic enzymes such as interstitial collagenase ${ }^{23}$ which would not be measured in our assay systems and possibly the down-regulation of general protease and collagenase IV activity. The profile of proteolytic enzymes can be altered by development in human mononuclear phagocytes. Peripheral blood monocytes contain a serine proteinase and cathepsin $G$ but have little capacity for the production of collagenase-degrading enzymes. ${ }^{24}$ As monocytes differentiate into macrophages, they lose the gene expression of serine enzymes and acquire the capacity to produce collagenase IV activity. ${ }^{24}$ It is possible that continued growth of $\mathrm{C} 6$ astrocytoma cells in an in vivo environment may also alter gene expression and account for the changes in proteolytic enzyme activity seen.

A number of metalloproteases can degrade collagen type IV. These include a 92-kilodalton gelatinase, a 72-kilodalton type IV collagenase and transin 1 and 2 which are the rat homologues of human stromelysin 1 and 2.23,25-27 Tissue inhibitors of metalloproteases (TIMPs) inhibit the function of these metalloproteinases $^{25,26}$ and two of these have been extensively characterized and studied (TIMP and TIMP-2). Although the relative contribution of individual metalloprotease to collagen IV degra-

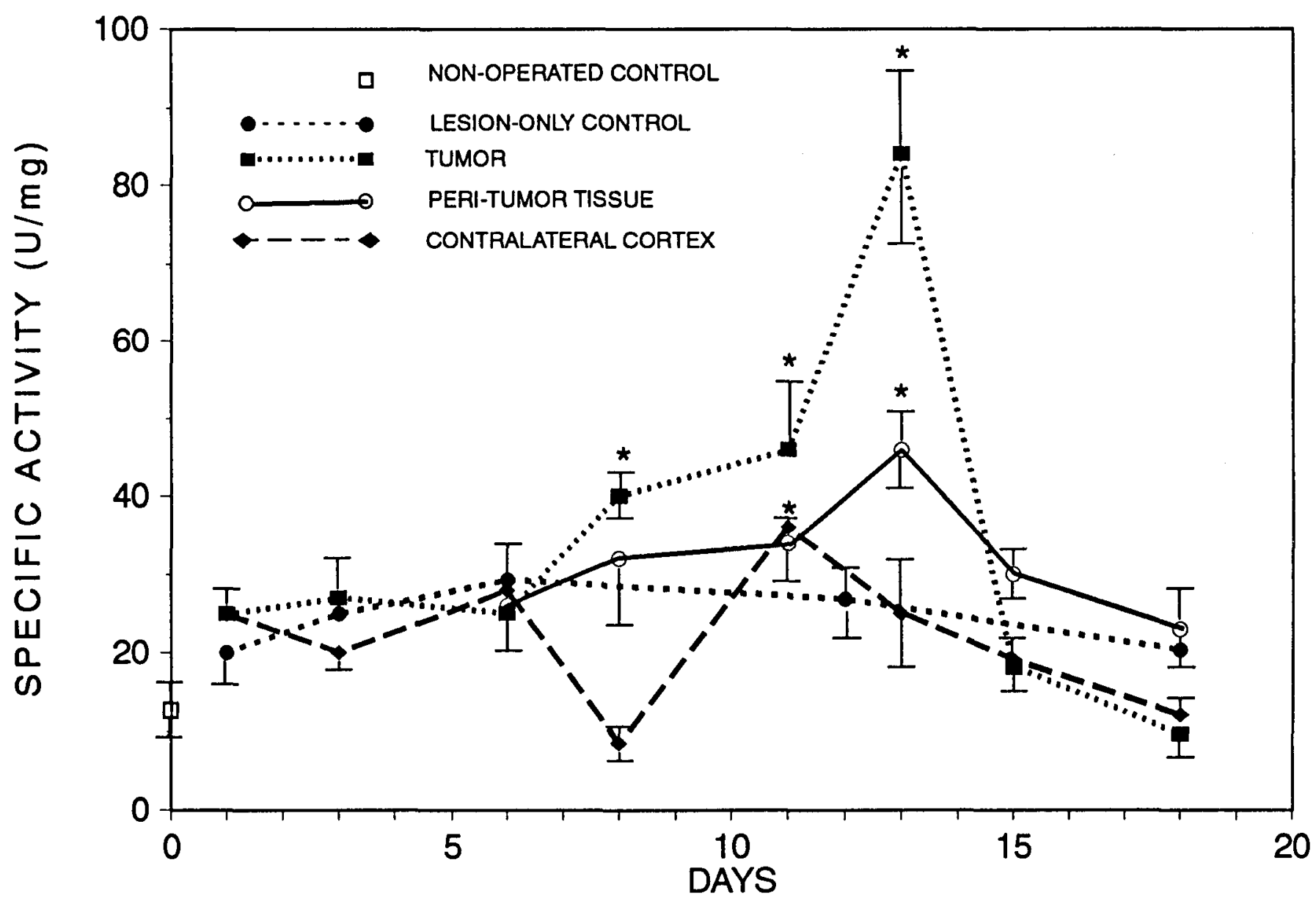

Figure 2 - Type IV collagenase degrading activity in non-operative cerebral tissue, lesion-only controls, tumor, peritumoral tissue and contralateral cortex during the growth of C6 astrocytoma cells in the spheroid implantation model. Values are means \pm standard error of the mean $(n=5)$. Significant differences $(p<0.01)$ from non-operative controls are indicated with an asterisk $(*)$. 
dation in this model is not known, no increase in inhibitor activity was measured in tumor tissue between day 13 and 18 (Vaithilingam, unpublished results). These results suggest that increased inhibitory activity is not the cause of the decreased collagenase IV activity found between day 13 and 18 and therefore there must be a down-regulation of collagenase IV activity. There does not appear to be a direct relationship between the size of the C6 intracerebral tumor and the levels of proteolytic activity measured in the study reported here. Alterations in the proteolytic activities measured appear to correlate more with initial angiogenesis in this model rather than vascular events occurring during the latter stages of tumor growth. The results from multiple time points of tissue sampling during the growth of the tumor suggest that there may be a cascade of proteolytic events occurring in this in vivo model which are not accurately predicted by the in vitro experiments or sampling of tissues at any one time point during the growth of the tumor. ${ }^{5}$

The pattern of activity observed in peritumoral tissue is similar to that found in tumor tissue. This suggests that either (i) the activities assessed in peritumoral tissue are the result of diffusion of extracellularly-released enzymes from tumor cells into the peritumoral microenvironment or (ii) that a factor or factors released by tumor cells increases the expression of these activities by having an autocrine function on $\mathrm{C} 6$ astrocytoma cells and a paracrine function on peritumoral cells, resulting in the enhanced transcription and release of the enzyme activities studied in both microenvironments or (iii) that an inhibitor or group of inhibitors ${ }^{22,25-27}$ of the proteolytic activities measured is being down-regulated by tumor cells in peritumoral tissue, resulting in increased proteolytic enzyme activities. The increased general protease activity measured in contralateral hemisphere tissue is difficult to explain solely by the diffusion of extracellularlyreleased enzyme from the tumor, and suggests the action of a diffusible factor(s) reaching the contralateral hemisphere by CSF or vascular pathways. This mode of communication may allow the tumor to influence biochemical functions in sites distant from the original tumor mass. No increase in microvessel density has been observed in the hemisphere contralateral to the implanted C6 astrocytoma spheroid. ${ }^{28}$ Increased proteolytic activity is only one component of a complex interactive series of events associated with tumor-induced angiogenesis, but is not sufficient in itself to result in new vessel formation. ${ }^{29}$

Metalloproteinase activity has been associated with the ability of human glioblastoma cells to invade cerebral tissues in a number of in vitro model systems. ${ }^{30}$ In these studies, metalloproteinase activity was not directly assessed, but 1, 10, 0-phenonthraline, an inhibitor of metalloproteases inhibited invasion.

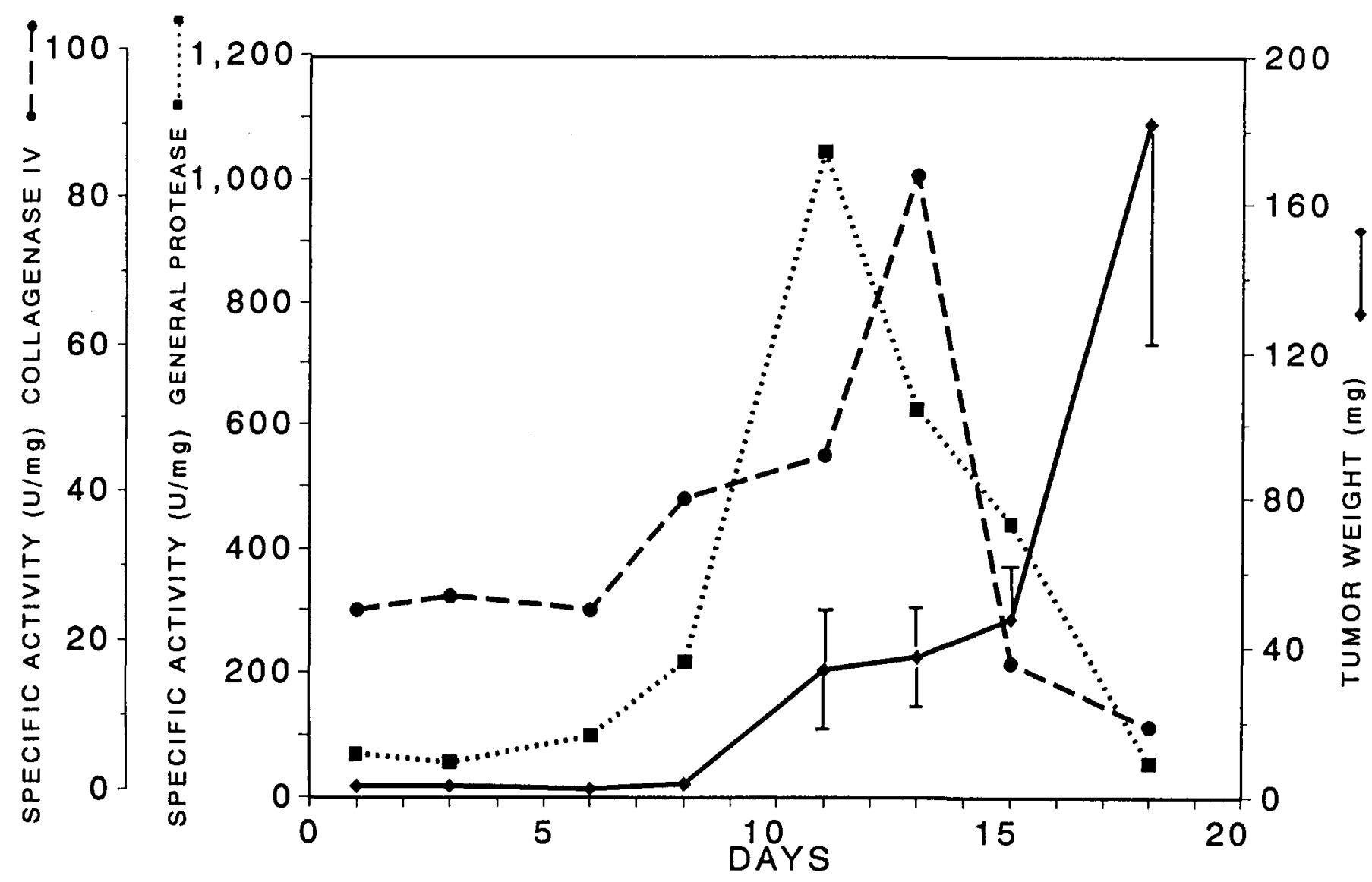

Figure 3-Mean general protease and type $I V$ degrading activity compared to the size of C6 astrocytoma tumors in the spheroid implantation model. Values for the tumor weights are means \pm standard error for the mean $(n=5)$. 
Halaka et al. ${ }^{31}$ found an inverse correlation between the levels of TIMP and the invasive potential of a number of human intracranial tumors. No increase in interstitial collagenase (which degrades collagen Type I, II and III) was seen in these studies, but collagenase IV was not assessed. Down-regulation of TIMP mRNA levels via antisense RNA converted a previously nontumorogenic and non-invasive Swiss 3T3 cell line to tumorogenic cells with invasive properties in vitro and metastatic properties in vivo. ${ }^{32}$ An understanding of the relationships between the non-specific and specific proteases involved in basement membrane degradation, along with their modulating systems, appears crucial to the understanding of the initiation events of tumor-induced angiogenesis and tumor invasion.

A cascade of proteolytic events orchestrated by tumor cells and possible other cells such as invading macrophages, ${ }^{24,33}$ and modulated by a number of inhibitors $22,25-27,34,35$ appear to be associated with in vivo C6 astrocytoma growth in the model system studied.

\section{ACKNOWLEDGEMENTS}

The authors would like to thank Jo-Ann Dunn for her secretarial assistance.The work was supported by the Brain Research Fund Foundation, the Victoria Hospital Research Development Fund and the Royal Arch Masons of Canada "Release a Miracle Donation to Medical Research". Dr. Del Maestro is a recipient of an Ontario Ministry of Health Career Scientist Award. Dr. I.S. Vaithilingam is a recipient of the Brain Research Fund Foundation Fellowship.

\section{REFERENCES}

1. Wang BS, McLoughlin GA, Richie JP, et al. Correlation of the production of plasminogen activator with tumor metastasis in B16 mouse melanoma cell lines. Cancer Res 1980; 40: 288-292.

2. Sloane BF, Bunn JR, Honn KV. Lysosomal cathepsin B: correlation with metastatic potential. Science 1981; 212: 1151-1153.

3. Turpeenniemi-Hujanen T, Thorgeirsson UP, Hart IR, et al Expression of collagenase IV (Basement Membrane Collagenase) activity in murine tumor cell hybrids that differ in metastatic potential. J Natl Cancer Inst 1985; 75: 99-103.

4. Thorgeirsson UP, Turpeenniemi-Hujanen T, Williams JE, et al. N1H-3T3 cells transfected with human tumor DNA containing activated ras oncogenes express the metastatic phenotype in nude mice. Mol Cell Biol 1985; 5: 259-262.

5. Vaithilingam IS, Stroude EC, McDonald W, et al. General protease and collagenase (IV) activity in C6 astrocytoma cells, C6 spheroids and implanted C6 spheroids. J Neuro-oncol 1991; 10: 203-212.

6. Del Maestro RF, Lopez-Torres M, McDonald W, et al. The effect of tumor necrosis factor- $\alpha$ on human malignant glial cells. J Neurosurg (in press).

7. Gimbrone MA Jr, Contran RS, Leapman SB, et al. Tumor and neovascularization: an experimental model using the rabbit cornea. $J$ Natl Cancer Inst 1974; 52: 413-428.

8. Ausprunk K, Knighton DR, Folkman J. Vascularization of normal and neoplastic tissues grafted to the chick chorioallantois. Am J Pathol 1975; 79: 597-618.

9. Weiss JB, Brown RA, Kumar S, et al. An angiogenic factor isolated from tumors: a potent low-molecular weight compound. $\mathrm{Br} \mathrm{J}$ Cancer 1979; 3: 493-496.

10 Folkman J, Cotran RS. Relation of vascular proliferation to tumor growth. Int Rev Exp Pathol 1976; 16: 207-248.

11. Folkman J. How is blood vessel growth regulated in normal and neoplastic tissue? G.H.A. Clowes Memorial Award Lecture. Cancer Res 1986; 46: 467-473.
12. Zetter BR. Migration of capillary endothelial cells is stimulated by tumor-derived factors. Nature $1980 ; 285: 41-43$.

13. Del Maestro RF, Megyesi JF, Farrell CL. Mechanisms of tumorassociated edema: a review. Can J Neurol Sci 1990; 17: 177-183.

14. Mignatti $P$, Robbins $E$, Rifkin DB. Tumor invasion through the human amniotic membrane: requirement for a proteinase cascade. Cell 1986; 47: 487-498.

15. Mignatti $P$, Tsuboi $R$, Robbins $E$, et al. In vitro angiogenesis on the human amniotic membrane: requirement for basic fibroblast growth factor-induced proteinases. J Cell Biol 1989; 108: 671682.

16. Bosman FT, Cluetjens J, Beek C, et al. Basement membrane heterogeneity. Histochem J 1989; 21: 629-633.

17. Farrell CL, Stewart PA, Del Maestro RF. A new glioma model in rat: the $\mathrm{C} 6$ astrocytoma spheroid implantation technique, permeability and vascular characterization. J Neuro-oncol $1987 ; 4$; 403-415.

18. Rice RH, Means GE. Radioactive labelling of proteins in vitro. J Biol Chem 1971; 246: 831-832.

19. Mallya SK, Mookhtiar KA, van Wart WE. Accurate quantitative assays for the hydrolysis of soluble type I, II, and III ${ }^{3} \mathrm{H}$-acetylated collagens by bacterial and tissue collagenases. Anal Biochem 1985; 158: 334-345.

20. Mookhtiar KA, Mallya SK, van Wart HE. Properties of radiolabelled type I, II, and III collagens related to their use as substrates in collagenase assays. Anal Biochem 1986; 158: 322-333.

21. Bradford MM. A rapid and sensitive method for quantitation of microgram quantities of protein utilizing the principle of proteindye binding. Anal Biochem 1976; 72: 248-254.

22. Thompson WD, Shiach JK, Fraser RA, et al. Tumors acquire their vasculature by vessel incorporation, not vessel ingrowth. J Pathol 1987; 151: 323-332.

23. Woessner JF Jr. Matrix metalloproteinases and their inhibitors in connective tissue remodelling. FASEB J 1991; 5: 2145-2154.

24. Senior RM, Griffin GL, Fliszar CJ, et al. Human 92- and 72-kilodalton type IV collagenases are elastases. J Biol Chem 1991; 266: 7870-7875.

25. DeClerck YA, Yean TD, Ratzkin BJ. Purification and characterization of two related but distinct metalloproteinase inhibitors secreted by bovine aortic endothelial cells. J Biol Chem 1989; 264: 17445-17453.

26. Stetler-Stevenson WG, Krutzsch HC, Liotta LA. Tissue inhibitor of metalloproteinase (TIMP-2): a new member of the metalloproteinase inhibitor family. J Biol Chem 1989; 264: 17374-17378.

27. Stetler-Stevenson WG. Type IV collagenases in tumor invasion and metastasis. Cancer Metabol Rev 1990; 9: 289-303.

28. Farrell CL. The microcirculation in a glioma model. Ph.D. Thesis. University of Western Ontario 1988.

29. Blood $\mathrm{CH}$, Zetter BR. Tumor interactions with the vasculature: angiogenesis and tumor metastasis. Biochem Biophys Acta 1990; 1032: 89-118.

30. Paganetti PA, Caroni P, Schwab ME. Glioblastoma infiltration into central nervous system tissue in vitro: involvement of a metalloprotease. J Cell Biol 1988; 107: 2281-2291.

31. Halaka AN, Bunning RAD, Bird CC. Production of collagenase and inhibitor (TIMP) by intracranial tumors and dura in vitro. $\mathrm{J}$ Neurosurg 1983; 59: 461-466.

32. Khokha R, Waterhouse $P$, Yagel S, et al. Antisense RNA-induced reduction in murine TIMP levels confers oncogenicity on Swiss 3T3 cells. Science 1989; 243: 947-950.

33. Polverini PJ, Leibovich SJ. Induction of neovascularization in vivo and endothelial proliferation in vitro by tumor-associated macrophages. Lab Invest 1984; 51: 635-642.

34. Liotta LA. Tumor invasion and metastases - Role of the extracellular matrix. Rhoads Memorial Award Lecture. Cancer Res 1986; 46: $1-7$

35. Testa JE, Quigley JP. Reversal of misfortune: TIMP-2 inhibits tumor cell invasion. J Natl Cancer Inst 1991; 83: 740-742. 